\title{
Stochastic Optimal Dispatch of Virtual Power Plant considering Correlation of Distributed Generations
}

\author{
Jie Yu, ${ }^{1}$ Qizhi Feng, ${ }^{1}$ Yang Li, ${ }^{1}$ and Jinde $\mathrm{Cao}^{2,3}$ \\ ${ }^{1}$ School of Electrical Engineering, Southeast University, Nanjing 210096, China \\ ${ }^{2}$ Department of Mathematics and Research Center for Complex Systems and Network Sciences, Southeast University, \\ Nanjing 210096, China \\ ${ }^{3}$ Department of Mathematics, Faculty of Science, King Abdulaziz University, Jeddah 21589, Saudi Arabia \\ Correspondence should be addressed to Jie Yu; yujie@seu.edu.cn
}

Received 22 October 2014; Revised 3 March 2015; Accepted 5 March 2015

Academic Editor: Hector Puebla

Copyright (C) 2015 Jie Yu et al. This is an open access article distributed under the Creative Commons Attribution License, which permits unrestricted use, distribution, and reproduction in any medium, provided the original work is properly cited.

\begin{abstract}
Virtual power plant (VPP) is an aggregation of multiple distributed generations, energy storage, and controllable loads. Affected by natural conditions, the uncontrollable distributed generations within VPP, such as wind and photovoltaic generations, are extremely random and relative. Considering the randomness and its correlation of uncontrollable distributed generations, this paper constructs the chance constraints stochastic optimal dispatch of VPP including stochastic variables and its random correlation. The probability distributions of independent wind and photovoltaic generations are described by empirical distribution functions, and their joint probability density model is established by Frank-copula function. And then, sample average approximation (SAA) is applied to convert the chance constrained stochastic optimization model into a deterministic optimization model. Simulation cases are calculated based on the AIMMS. Simulation results of this paper mathematic model are compared with the results of deterministic optimization model without stochastic variables and stochastic optimization considering stochastic variables but not random correlation. Furthermore, this paper analyzes how SAA sampling frequency and the confidence level influence the results of stochastic optimization. The numerical example results show the effectiveness of the stochastic optimal dispatch of VPP considering the randomness and its correlations of distributed generations.
\end{abstract}

\section{Introduction}

The continuing growth of energy consumption and environmental pollution spurs the application of distributed generations. But with more and more distributed generations connecting into the power grid, it became a serious problem to effectively manage a number of diffuse and different distributed generations, which maybe impede the green energy application. Virtual power plant (VPP) provides a practical and feasible solution to operational management of massive distributed generations, so as to make full use of distributed generations and increase the reliability of power supply. Conceptually, VPP is the collection of multiple decentralized distributed generations, energy storage, and some loads, with the characteristic of controllability like conventional power plants. Currently, the VPP is still in theoretical research and early stage of the pilot phase. Early VPP project [1] is mainly concentrated in Europe and the United States, whose research content focuses on interactive information architecture [2], operation control architecture [3], auxiliary services [4], and VPP energy management optimization scheduling.

VPP, whose essence is energy management schedule, should realize the optimal generation coordination among distributed generations, controllable loads, and storage devices within itself [5]. VPP contains a number of distributed generations with different types and different features, so the VPP energy management becomes more complicated than traditional power plants. From the view of optimization, the VPP optimal dispatch mainly focuses on the VPP costs minimum or profits maximum. The uncontrolled distributed 
generations within the VPP, such as wind and photovoltaic, show strong random features affected by natural conditions. The uncertainties need to be given full consideration in the process of VPP optimization scheduling. Vasirani et al. [6] consider electric vehicles to balance the uncertainty of wind generation in the VPP dispatch, which participates in shortterm power market. The VPP studied by Shropshire et al. [7] contains a coastal wind farm and a small medium scaled nuclear power plant, so the nuclear power would effectively stabilize the volatility of wind generation. Houwing et al. [8] use deterministic power generation, such as microgas turbine, to burden the volatility of wind generation. From the perspective of demand side, Mohammadi et al. [9] apply flexible loads to counteract the effects of wind generation uncertainties in a VPP. Peikherfeh et al. [10], thinking of the uncertainty caused by distributed generation prediction error, deal with it by VPP spare capacity schedule. Other researchers construct VPP stochastic optimal dispatch, which previously focuses on VPP expectation [11], chance constrained [12], and two-stage stochastic optimization model [13-15]. Pandžić et al. [13], considering the uncertainty of distributed generations and electricity prices in the power market, build VPP two-stage stochastic optimization model with the goal of VPP profits maximum. A little similar VPP stochastic optimization model is built by Handschin et al. [14], aiming at VPP, costs minimum with the constraint conditions that not only contains electrical balance but also considers thermal equilibrium. Moghaddam et al. [15] provide a day-ahead optimal schedule for VPP systems containing wind generations and hydropower units.

Within the same region, distributed generations, consisting of VPP, theoretically have output power correlations due to the geographical proximity. But seldom research results considering correlations of distributed generations are published till now. This paper analyzes the problem of VPP optimal dispatch based on the correlations between wind and photovoltaic generations. The probability distributions of independent wind and photovoltaic generations are described by empirical distribution functions, and their joint probability density models are established with Frank-copula function according to their joint histogram and Squared Euclidean Distance. Containing random variables and their correlations, VPP stochastic optimization model is built. Based on sample average approximation (SAA), VPP chance constrained stochastic optimization model is converted into a deterministic optimization model. Numerical cases show effective results.

\section{The Randomness and Correlations in VPP}

The wind and photovoltaic generations in VPP have strong randomness and correlations affected by natural conditions. The probability distributions of independent wind and photovoltaic generations could be described by empirical distribution functions, and copula function could be applied to quantitatively define the corrections of them. The empirical distribution functions are shown as follows:

$$
\begin{aligned}
& F\left(p_{m}\right) \\
& \quad= \begin{cases}0 & p_{m}<p_{m(\min )} \\
\sum_{k=1}^{n} f_{k} & p_{m(l)}<p_{m}<p_{m(l+1)}, \quad(l=1,2, \ldots, n-1) \\
1 & p_{m}>p_{m(\max )} .\end{cases}
\end{aligned}
$$

Copula theory was proposed by Sklar in 1959, who pointed that any $n$-dimensional joint cumulative distribution function can be divided into $n$ marginal cumulative distribution and a copula function. The marginal cumulative distribution describes the distribution of the variables, and the copula function describes the correlations of the variables, listed as follows:

$$
\begin{aligned}
& F\left(x_{1}, \ldots, x_{n}, \ldots, x_{N}\right) \\
& \quad=C\left(F_{1}\left(x_{1}\right), \ldots, F_{n}\left(x_{n}\right), \ldots, F_{N}\left(x_{N}\right)\right),
\end{aligned}
$$

where $F\left(x_{1}, x_{2}, \ldots, x_{N}\right)$ is the joint probability distribution function of $\left(x_{1}, x_{2}, \ldots, x_{N}\right) . F_{1}\left(x_{1}\right), F_{2}\left(x_{2}\right), \ldots, F_{N}\left(x_{N}\right)$ are the probability distribution function of single variable $x_{1}, x_{2}, \ldots, x_{N}$. C denotes the copula function.

Normality-copula, $t$-copula, and Archimedes-copula are the most frequently used type of copula function.

(1) Normality-copula function is as follows:

$$
\begin{aligned}
C & \left(u_{1}, u_{2}, \ldots, u_{N} ; \rho\right) \\
& =\Phi_{\rho}\left(\Phi^{-1}\left(u_{1}\right), \Phi^{-1}\left(u_{2}\right), \ldots, \Phi^{-1}\left(u_{N}\right)\right),
\end{aligned}
$$

where $\rho$ is the symmetric positive definite matrix whose diagonal elements are $1 . \Phi_{\rho}$ is the standard normal distribution function whose correlation coefficient matrix is $\rho$, whose marginal distribution is standard normal distributions. $\Phi^{-1}$ is the inverse function of standard normal distribution function.

(2) $t$-copula function is as follows:

$$
\begin{aligned}
C & \left(u_{1}, u_{2}, \ldots, u_{N} ; \rho, k\right) \\
& =t_{\rho, k}\left(t_{k}^{-1}\left(u_{1}\right), t_{k}^{-1}\left(u_{2}\right), \ldots, t_{k}^{-1}\left(u_{N}\right)\right),
\end{aligned}
$$

where $\rho$ is the symmetric positive definite matrix whose diagonal elements are all ones. $t_{\rho, k}$ is the $t$ distribution function, whose correlation coefficient matrix is $\rho$ and degrees of freedom are $k . t_{k}^{-1}$ is the inverse function of $t$ distribution function whose degrees of freedom are $k$.

(3) Archimedes-copula function is as follows:

$$
\begin{aligned}
& C\left(u_{1}, u_{2}, \ldots, u_{N}\right) \\
& \quad= \begin{cases}\phi^{-1}\left[\phi\left(u_{1}\right), \phi\left(u_{2}\right), \ldots, \phi\left(u_{N}\right)\right], & \sum_{i=1}^{N} \phi\left(u_{i}\right) \leq \phi(0) \\
0, & \text { others, }\end{cases}
\end{aligned}
$$


where $\varphi(u)$, as a convex decreasing function, is the generator of Archimedes function. $\varphi^{-1}(u)$ is the inverse function of $\varphi(u)$. Among the different types of Archimedes-copula function, Gumbel-copula, Clayton-copula, and Frank-copula are the most frequently applied.

(a) Gumbel-copula is as follows:

$$
C(u, v)=\exp \left\{-\left[(-\ln u) \alpha+(-\ln v)^{\alpha}\right]^{1 / \alpha}\right\}
$$

(b) Clayton-copula is as follows:

$$
C(u, v)=\max \left[\left(u^{\alpha}+v^{\alpha}-1\right)^{-1 / \alpha}, 0\right]
$$

(c) Frank-copula is as follows:

$$
C(u, v)=-\frac{1}{\alpha} \ln \left[1+\frac{\left(e^{-\alpha u}-1\right)\left(e^{-\alpha v}-1\right)}{e^{\alpha}-1}\right]
$$

where $u, v$ are the empirical distribution functions of random variables and $\alpha$ indicates the connection parameters of the joint distribution.

Different copula function can describe different correlation of the random variables, so we need to select the optimal copula function to describe the correlation of specific variables. Squared Euclidean Distance is applied to select the optimal copula function. Firstly, the Squared Euclidean Distance of all kinds of theoretical copula and empirical copula function are calculated. The smallest distance theoretical copula is the optimal copula to describe the correlations of variables. The expression of Squared Euclidean Distance is listed as follows:

$$
d^{2}=\sum_{i=1}^{n}|\widetilde{C}(u, v)-C(u, v)|^{2}
$$

where $\widetilde{C}(u, v)$ expresses the empirical copula of variables. $C(u, v)$ denotes the theoretical copula of them.

\section{VPP Stochastic Optimal Dispatch Mathematic Model}

The VPP contains a number of uncontrollable generations, such as wind and photovoltaic and controllable generations, such as fuel cell and diesel generators, as well as batteries as energy storage devices. The aim of VPP dispatch model is to maximize the profits of VPP, considering the power grid constraints, the operating constraints of generations, and the energy storage constraints. In view of stochastic generation feature of the uncontrollable generations (wind and photovoltaic), VPP dispatch model would be constructed as stochastic optimal mathematic model as follows.

\subsection{Objective Function. Consider}

$$
\begin{aligned}
\max F & =\rho_{\text {plan }} P_{\text {plan }}+\rho_{\text {load }} P_{\text {load }}-C_{F} \\
& =\rho_{\text {plan }} P_{\text {plan }}+\rho_{\text {load }} P_{\text {load }}-\sum_{i=1}^{N} C_{i}\left(P_{i}\right)-C_{i}^{M} P_{i},
\end{aligned}
$$

where $\rho_{\text {plan }}$ is the power energy price from VPP selling to the power grid. $\rho_{\text {load }}$ is the load energy price bought by the customers from VPP. $P_{\text {plan }}$ means the plan generation that VPP submits to the power grid control center. $P_{\text {load }}$ represents interior loads in VPP. $P_{i}$ means the output generation of distributed generator $i$ in the VPP. $C_{i}^{M}$ is the maintenance costs of distributed generator $i$ in the VPP. $C_{i}\left(P_{i}\right)$ indicates the fuel costs function of distributed generator $i$. The expressions of fuel cells and diesels are as follows.

(1) The costs function of fuel cell is as follows:

$$
C_{\mathrm{FC}}\left(P_{\mathrm{FC}}\right)=C_{\mathrm{LHV}} \times \frac{1}{\mathrm{LHV}} \times P_{\mathrm{FC}},
$$

where $C_{\mathrm{FC}}\left(P_{\mathrm{FC}}\right)$ denotes the fuel costs of fuel cell. $C_{\mathrm{LHV}}$ expresses the price of natural gas per unit volume. LHV is the abbreviation of the calorific value of natural gas. $P_{\mathrm{FC}}$ means the output generation of fuel cell.

(2) The costs function of the diesel is as follows:

$$
C_{\mathrm{DE}}\left(P_{\mathrm{DE}}\right)=a \times P_{\mathrm{DE}}^{2}+b \times P_{\mathrm{DE}}+c,
$$

where $C_{\mathrm{DE}}\left(P_{\mathrm{DE}}\right)$ denotes the fuel costs of diesel. $a, b$, and $c$ are the coefficients of cost function. $P_{\mathrm{DE}}$ means the output generation of the diesel.

3.2. Constraints. (1) The generation plan constraint is formulated in (13). The VPP, undertaking power generation like traditional power plants, outputs power generation according to the generation plan from the power grid control center. VPP outputs would be determined by the total generation of all distributed generator $i$ (in the VPP) subtracting the load (in the VPP):

$$
\sum_{i=1}^{N} P_{i}-P_{\text {load }}=P_{\text {plan }}
$$

(2) The upper and lower limits of each controllable distributed generation are as follows:

$$
P_{i}^{\min }<P_{i}<P_{i}^{\max }
$$

$P_{i}^{\min }, P_{i}^{\max }$ represent the upper and lower limits, respectively.

(3) The operating constraints of uncontrollable distributed generation are as follows:

$$
\operatorname{Pr}\left\{p_{w} \leq P_{w, \max }, p_{\mathrm{pv}} \leq P_{\mathrm{pv}, \max }\right\} \geq \alpha,
$$

where $P_{w, \max }, P_{\mathrm{pv}, \max }$ represent the upper limits of wind and photovoltaic generations respectively, whose output power 
TABLE 1: Initial data of controllable distributed generations.

\begin{tabular}{|c|c|c|c|c|}
\hline \multirow{2}{*}{$\begin{array}{l}\text { Types of controllable distributed } \\
\text { generation }\end{array}$} & \multirow{2}{*}{ Rated power/kW } & \multicolumn{2}{|c|}{ Technical output/kW } & \multirow{2}{*}{$\begin{array}{c}\text { Operation and maintenance } \\
\text { coefficient/æ/kWh }\end{array}$} \\
\hline & & Lower limit & Upper limit & \\
\hline Fuel cell & 160 & 0 & 500 & 0.0293 \\
\hline Diesel generator & 200 & 0 & 600 & 1 \\
\hline \multicolumn{5}{|c|}{ Natural gas, calorific value: $10.47 \mathrm{kWh} / \mathrm{m}^{3}$, and price: $3.3 ¥ / \mathrm{m}^{3}$} \\
\hline \multicolumn{5}{|c|}{ The power-cost curve parameters of diesel generator: $a=0.0015, b=1.43$, and $c=1$} \\
\hline \multicolumn{5}{|c|}{ Power price in the power grid: $0.49 ¥ / \mathrm{kW}$ and power price for customers: $0.78 ¥ / \mathrm{kW}$} \\
\hline
\end{tabular}

generation meets the copula joint probability distributed $\operatorname{Pr}\{\cdot\}$ denotes the probability values of inequality. $\alpha$ is the confidence level, which is given in advance.

(4) Power energy storage constraints are as follows:

$$
\begin{gathered}
P_{\text {BT_ch }}^{\min } \leq P_{\text {BT_ch }} \leq P_{\text {BT_ch }}^{\max }, \\
P_{\text {BT_disch }}^{\min } \leq P_{\text {BT_disch }} \leq P_{\text {BT_disch }}^{\max },
\end{gathered}
$$

where $P_{\mathrm{BT} \text { _ch }}, P_{\mathrm{BT} \text { _disch }}$ represent the charge and discharge power of the battery, respectively. $P_{\mathrm{BT} \text { _ch }}^{\min }, P_{\mathrm{BT}}^{\max }$ dh denote the upper and lower limits of charging power. $P_{\mathrm{BT} \text { _disch }}^{\min }, P_{\mathrm{BT} \text { _disch }}^{\max }$ denote the upper and lower limits of discharging power.

\section{Solution Methods and Process}

Sample average approximation (SAA) is an effective method based on Monte Carlo simulation to solve stochastic optimization. This method used sample average function to approximately substitute the expected value of the function and specifically use Monte Carlo to generate sample values. Firstly, the average values of the corresponding function are calculated based on the sample values. And then it was determined whether the mean function satisfies the probability, so as to convert the uncertain chance constraints of probability factors into certain constraints. The main solving steps of this method are listed as follows.

(1) Sample $Q$ groups of wind and photovoltaic outputs power from copula joint probability distributed and shown as $\left(p_{w j}, p_{\mathrm{pv} j}\right)(j=1,2, \ldots, Q)$.

(2) Calculate the number of samples which satisfies the constraints used indicator function $I(t)$. When the value of the samples satisfies the constraints, $I(t)$ is 1 . Otherwise, $I(t)$ is 0 :

$$
I_{(0, \infty)}(t)= \begin{cases}1, & \text { if } 0 \leq p_{w} \leq P_{w}^{\max }, 0 \leq p_{\mathrm{pv}} \leq P_{\mathrm{pv}}^{\max } \\ 0, & \text { others. }\end{cases}
$$

(3) Calculate the probability that the samples satisfied the constraints. The probability is written as $\overline{\operatorname{Pr}_{Q}}$ :

$$
\begin{aligned}
\overline{\operatorname{Pr}_{\mathrm{Q}}} & =E\left\{I_{(0, \infty)}\left[0 \leq p_{w} \leq P_{w}^{\max }, 0 \leq p_{\mathrm{pv}} \leq P_{\mathrm{pv}}^{\max }\right]\right\} \\
& =\frac{1}{\mathrm{Q}} \sum_{q=1}^{\mathrm{Q}} I_{(0, \infty)}\left[0 \leq p_{w} \leq P_{w}^{\max }, 0 \leq p_{\mathrm{pv}} \leq P_{\mathrm{pv}}^{\max }\right] .
\end{aligned}
$$

TABLE 2: Initial data of battery.

\begin{tabular}{lccc}
\hline $\begin{array}{l}\text { Battery } \\
\text { capacity/kWh }\end{array}$ & $\begin{array}{c}\text { Rated } \\
\text { power/kW }\end{array}$ & $\begin{array}{c}\text { Depth limit of } \\
\text { discharge and } \\
\text { charge capacity }\end{array}$ & $\begin{array}{c}\text { Maximum height } \\
\text { of discharge and } \\
\text { charge pulse }\end{array}$ \\
\hline 160 & 40 & 0.8 & 1 \\
\hline
\end{tabular}

(4) Convert the original uncertainty constraint into certainty constraints:

$$
\begin{aligned}
\operatorname{Pr} & \left\{p_{w} \leq P_{w, \text { max }}, 0 \leq p_{\mathrm{pv}} \leq P_{\mathrm{pv}, \max }\right\} \\
& =\frac{1}{\mathrm{Q}} \sum_{q=1}^{\mathrm{Q}} I_{(0, \infty)}\left[p_{w} \leq P_{w, \max }, 0 \leq p_{\mathrm{pv}} \leq P_{\mathrm{pv}, \max }\right] \geq \alpha .
\end{aligned}
$$

(5) Judge whether $\overline{\operatorname{Pr}_{Q}}$ satisfies $\overline{\operatorname{Pr}_{Q}} \geq \alpha$. If it is satisfied, SAA method is applied to obtain the average outputs power of wind and photovoltaic generations. $\overline{p_{m}}=$ $(1 / Q) \sum_{q=1}^{Q} p_{m}^{q}(m=w / p v)$ describes the expected values of wind and photovoltaic generations. Otherwise, return to (1) to recalculate.

\section{Numerical Cases}

5.1. Initial Data. In this paper's numerical cases, the VPP contains a wind farm, a photovoltaic station, a fuel cell, a diesel generator, and the storage device-battery. The related data information is listed in Tables 1 and 2.

\subsection{Randomness and Correlation of Wind and Photovoltaic} Generation. In this paper, the wind farm within the VPP contains 10 wind generation units, and the photovoltaic station consists of 10 photovoltaic cell units. The rate power of single wind generation unit is $30 \mathrm{~kW}$, and upper power is $50 \mathrm{~kW}$. The rated power of single photovoltaic cell unit is $40 \mathrm{~kW}$, and the upper power is $60 \mathrm{~kW}$. Based on the actual data of wind and photovoltaic generation in 1-10 March 2014, we can get the probability distribution histogram, the experience distribution, and the joint probability histogram shown in Figures 1-5, respectively.

In Figure 5, the complementary symmetry characters between the wind and photovoltaic generations are shown, whose shape fits the characters of Frank-copula. Furthermore, the Squared Euclidean Distance of all kinds of theoretical copula and empirical copula function are calculated. 


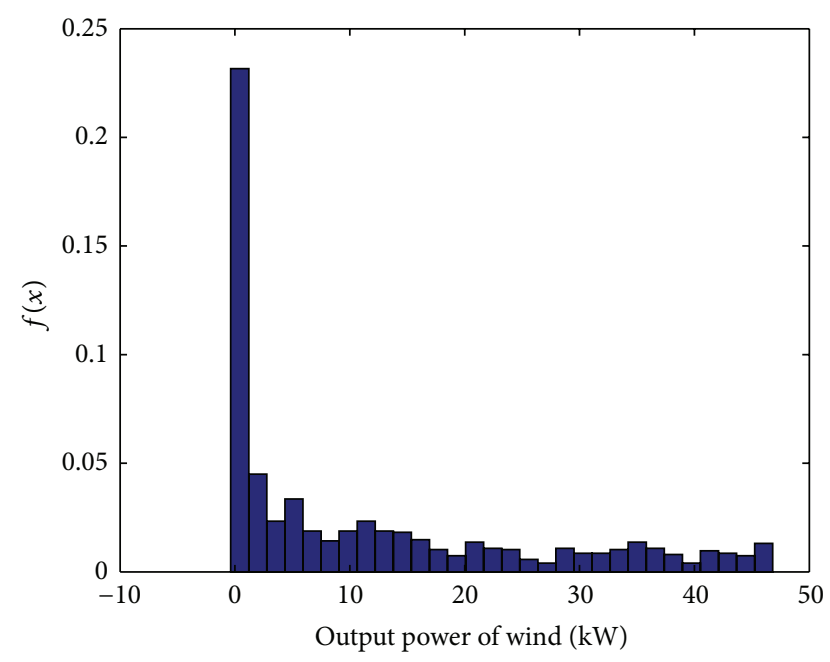

FIGURE 1: The probability distribution histogram of wind outputs.

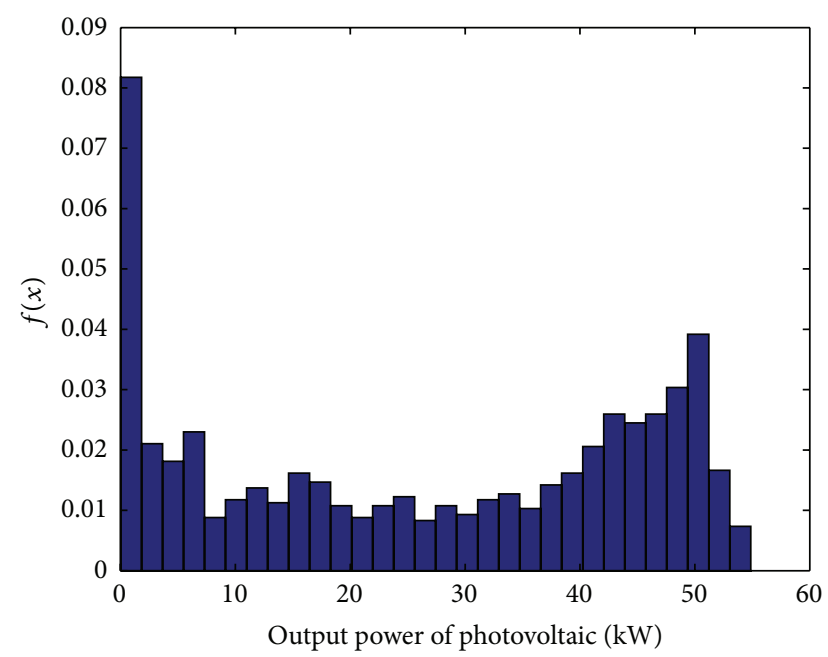

FIGURE 2: The probability distribution histogram of photovoltaic outputs.

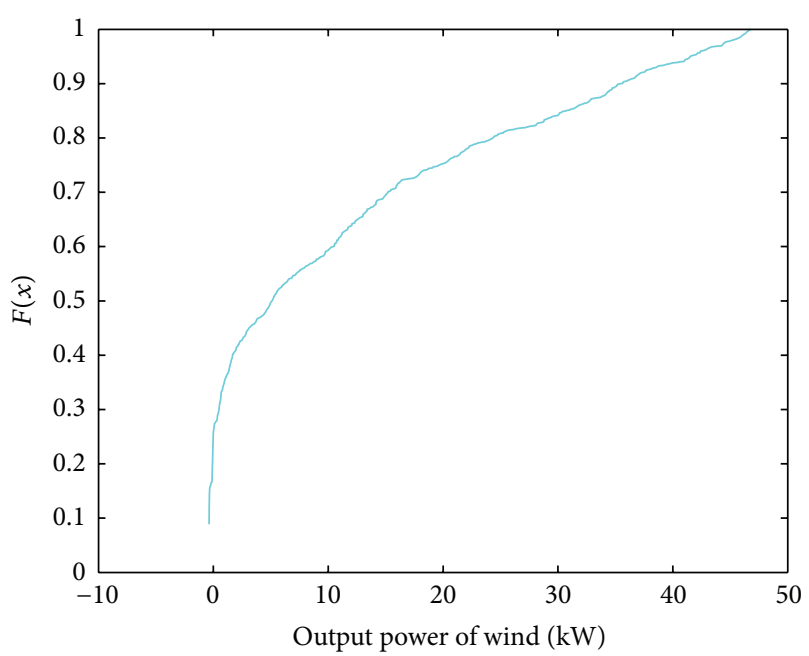

Figure 3: The experience distribution of wind outputs.

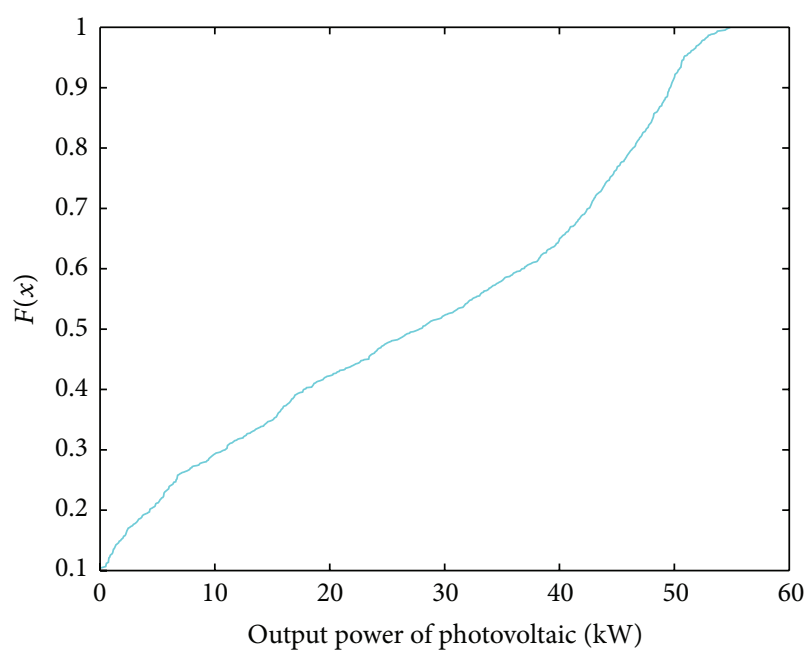

FIGURE 4: The experience distribution of photovoltaic outputs.

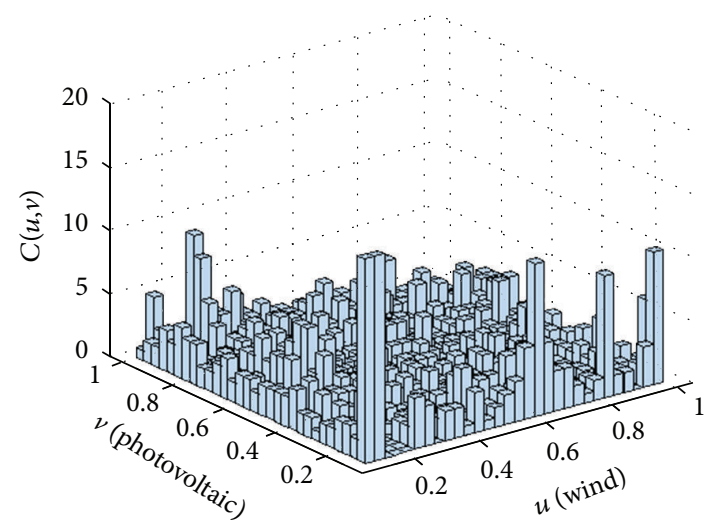

FIGURE 5: The joint probability histogram of wind and photovoltaic output.

TABle 3: The Squared Euclidean Distance between different kinds of theoretical copula and empirical copula functions denoting wind and photovoltaic generations.

\begin{tabular}{lcccc}
\hline Copula function & $\begin{array}{c}\text { Frank- } \\
\text { copula }\end{array}$ & $\begin{array}{c}\text { Gaussian- } \\
\text { copula }\end{array}$ & $\begin{array}{c}\text { Gumbel- } \\
\text { copula }\end{array}$ & $\begin{array}{c}\text { Clayton- } \\
\text { copula }\end{array}$ \\
\hline $\begin{array}{l}\text { Squared } \\
\begin{array}{l}\text { Euclidean } \\
\text { Distance }\end{array}\end{array}$ & 0.1496 & 0.1687 & 0.2631 & 0.2631 \\
\hline
\end{tabular}

And then, the smallest distance theoretical copula is selected as the best copula to describe the correlations of wind and photovoltaic generations.

After calculating, the Squared Euclidean Distance between different kinds of theoretical copula functions and empirical copula functions denoting wind and photovoltaic generations were listed in Table 3. It is clear that the Squared Euclidean Distance between Frank-copula and empirical copula is the smallest, which means that choosing Frankcopula is the most accurate to simulate the outputs of wind and photovoltaic generations. 


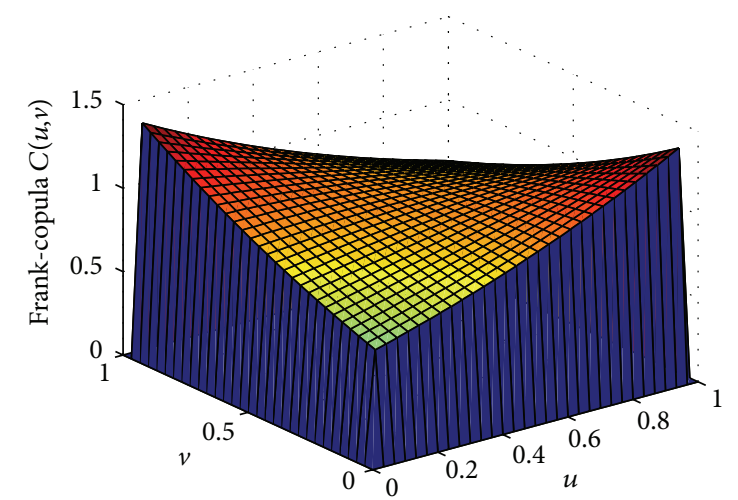

Figure 6: Frank-copula probability density of wind and photovoltaic output.

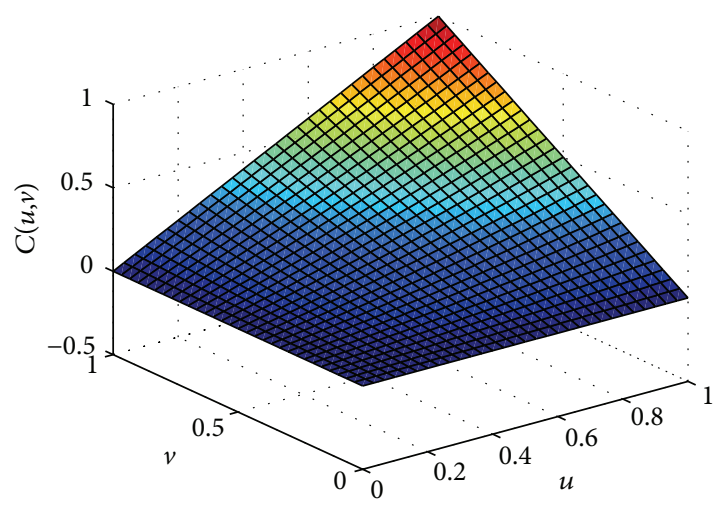

FIGURE 7: Frank-copula joint probability distribution of wind and photovoltaic generations.

Consequently, we choose Frank-copula to build the joint probability distribution model of wind and photovoltaic generations, expressed as (20). Frank-copula joint probability density and Frank-copula copula joint probability distribution as well as empirical probability distribution are shown in Figures 6-8, respectively,

$$
\begin{aligned}
H\left(p_{w}, p_{\mathrm{pv}}\right) & =C\left(F_{1}\left(p_{w}\right), F_{2}\left(p_{\mathrm{pv}}\right)\right) \\
& =-\frac{1}{\alpha} \ln \left(1+\frac{\left(e^{-\alpha F_{1}\left(p_{w}\right)}-1\right)\left(e^{-\alpha F_{2}\left(p_{\mathrm{pv}}\right)}-1\right)}{e^{-\alpha}-1}\right),
\end{aligned}
$$

where $C$ is the Frank-copula function. $p_{w}, p_{\mathrm{pv}}$ represent the outputs of wind and photovoltaic generations, respectively, which all obey $(1) . F_{1}\left(p_{w}\right), F_{2}\left(p_{\mathrm{pv}}\right)$ express the empirical distribution functions of $p_{w}, p_{\mathrm{pv}}$. A indicates the connection parameters of the joint distribution, and it is -0.8924 here.

5.3. Results and Analysis. Based on SAA, VPP stochastic optimal dispatch model is converted into a deterministic linear optimization model, which could be effectively solved by AIMMS. AIMMS is optimization simulation software, whose development environment possesses a unique combination

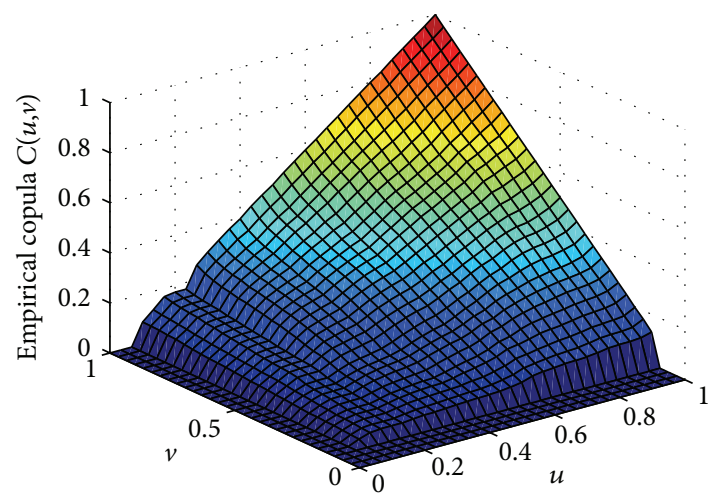

FIGURE 8: Empirical probability distribution of wind and photovoltaic generations.

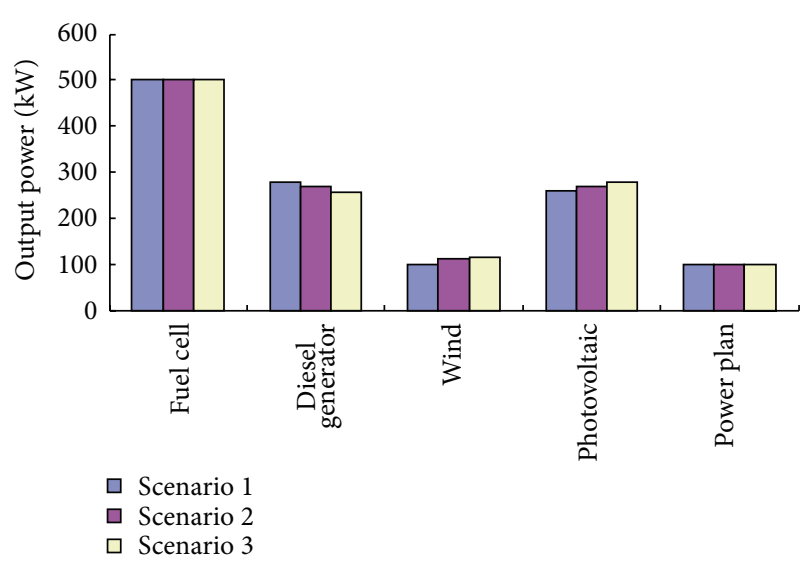

FIGURE 9: Different kinds of generations in the three scenarios.

of advanced features and design tools, such as automatically calling CPLEX to solve optimal model.

In three scenarios, the VPP optimal simulation results are analyzed. In Scenario 1, the randomness and correlation of wind and photovoltaic are not considered. In Scenario 2, the randomness of wind and photovoltaic power generation is considered, but not the correlation (the confidence level of wind and photovoltaic is 0.95 and the sampling frequency in SAA is 300). In Scenario 3, both the randomness and correlation of wind and photovoltaic power generation are considered (the confidence level is 0.95 and the sampling frequency in SAA is 300).

(1) The VPP Optimal Results in Different Scenarios. The VPP profits and the outputs of each generation are listed in Table 4 and Figure 9. The VPP profit in Scenario 1 is $18 ¥$, which is lower than Scenario 2 (46¥). But the profit in Scenario 2 is lower than Scenario 3 (87¥). From Figure 9 we can see that the outputs of wind and photovoltaic in Scenario 3 are higher than the other two cases, but the output of diesel generator decreased. The reason is that the stochastic optimal dispatch considering correlation can improve the utilization of uncontrollable distributed generations, so as to improve 
TABLE 4: The VPP optimal results in different scenarios.

\begin{tabular}{lccccccc}
\hline Scenarios & $\begin{array}{c}\text { Wind } \\
(\mathrm{kW})\end{array}$ & $\begin{array}{c}\text { Photovoltaic } \\
(\mathrm{kW})\end{array}$ & $\begin{array}{c}\text { Diesel generator } \\
(\mathrm{kW})\end{array}$ & $\begin{array}{c}\text { Fuel cell } \\
(\mathrm{kW})\end{array}$ & $\begin{array}{c}\text { Power output to the main grid } \\
(\mathrm{kW})\end{array}$ & $\begin{array}{c}\text { Costs } \\
(¥)\end{array}$ & $\begin{array}{c}\text { Profits } \\
(¥)\end{array}$ \\
\hline Scenario 1 & 100 & 260 & 278.83 & 497 & 100 & 936 \\
Scenario 2 & 111.17 & 268.84 & 269.99 & 497 & 100 & 18 \\
Scenario 3 & 115.86 & 276.76 & 257.38 & 497 & 100 & 908 \\
\hline
\end{tabular}

TABLE 5: The VPP optimal results in confidence levels.

\begin{tabular}{|c|c|c|c|c|c|c|c|}
\hline $\begin{array}{l}\text { Confidence } \\
\text { levels }\end{array}$ & $\begin{array}{l}\text { Wind farm } \\
(\mathrm{kW})\end{array}$ & $\begin{array}{c}\text { Photovoltaic station } \\
(\mathrm{kW})\end{array}$ & $\begin{array}{c}\text { Diesel generator } \\
(\mathrm{kW})\end{array}$ & $\begin{array}{c}\text { Fuel cell } \\
(\mathrm{kW})\end{array}$ & $\begin{array}{l}\text { Power output to the power grid } \\
\qquad(\mathrm{kW})\end{array}$ & $\begin{array}{c}\text { Costs } \\
(¥)\end{array}$ & $\begin{array}{c}\text { Profits } \\
(¥)\end{array}$ \\
\hline 0.90 & 118.24 & 280.43 & 251.33 & 497 & 100 & 830 & 106 \\
\hline 0.95 & 117.04 & 278.08 & 254.68 & 497 & 100 & 840 & 96 \\
\hline 0.97 & 116.42 & 276.85 & 256.73 & 497 & 100 & 847 & 89 \\
\hline 0.99 & 115.86 & 276.76 & 257.38 & 497 & 100 & 867 & 87 \\
\hline
\end{tabular}

the whole profits of VPP. The simulations in Table 4 are calculated while fixing the confidence level as 0.9.

(2) The VPP Optimal Results in Different Confidence Level of Scenario 3. Table 5 shows the profits of VPP under different confidence levels. The profits of VPP become higher with chance constrained confidence level lower. That means the whole profits could be increased by decreasing the confidence level appropriately.

\section{Conclusion}

Theoretically, VPP can effectively solve the issues concerning large-scale distributed generations connected to the power grid. In this paper, we proposed a stochastic optimal dispatch model of VPP considering correlations between uncontrollable distributed generations, such as wind and photovoltaic generations. In different scenarios, the VPP optimal results are compared and analyzed. The empirical distribution functions are used to properly describe the randomness and volatility of wind and photovoltaic generations, and the Frank-copula function is effectively applied to portray the complementary and symmetry of their correlations. Compared with deterministic optimal dispatch, the stochastic optimal dispatch proposed in this paper can improve the operating profits of the VPP and guarantee the security, robustness, and flexibility of VPP. On the other hand, the confidence level may also affect the VPP stochastic optimal dispatch, which is important to set the confidence level appropriately in actual operation based on the needs of VPP and the accuracy requirements.

\section{Conflict of Interests}

The authors declare that there is no conflict of interests regarding the publication of this paper.

\section{Acknowledgments}

This paper is supported by the National Natural Science Funds 51407030 and China Postdoctoral Science Foundation 121809.

\section{References}

[1] P. Asmus, "Microgrids, virtual power plants and our distributed energy future," The Electricity Journal, vol. 23, no. 10, pp. 72-82, 2010.

[2] S. Sučić, T. Dragičević, T. Capuder, and M. Delimar, "Economic dispatch of virtual power plants in an event-driven serviceoriented framework using standards-based communications," Electric Power Systems Research, vol. 81, no. 12, pp. 2108-2119, 2011.

[3] T. L. Vandoorn, B. Zwaenepoel, J. D. M. de Kooning, B. Meersman, and L. Vandevelde, "Smart microgrids and virtual power plants in a hierarchical control structure," in Proceedings of the 2nd IEEE PES International Conference and Exhibition on Innovative Smart Grid Technologies (ISGT Europe '11), pp. 1-7, Manchester, UK, December 2011.

[4] H. Khan, S. Dasouki, V. Sreeram, H. H. C. Iu, and Y. Mishra, "Universal active and reactive power control of electronically interfaced distributed generation sources in virtual power plants operating in grid-connected and islanding modes," IET Generation, Transmission \& Distribution, vol. 7, no. 8, pp. 885897, 2013

[5] D. Pudjianto, C. Ramsay, and G. Strbac, "Virtual power plant and system integration of distributed energy resources," IET Renewable Power Generation, vol. 1, no. 1, pp. 10-16, 2007.

[6] M. Vasirani, R. Kota, R. L. G. Cavalcante, S. Ossowski, and N. R. Jennings, "An agent-based approach to virtual power plants of wind power generators and electric vehicles," IEEE Transactions on Smart Grid, vol. 4, no. 3, pp. 1314-1322, 2013.

[7] D. Shropshire, A. Purvins, I. Papaioannou, and I. Maschio, "Benefits and cost implications from integrating small flexible nuclear reactors with off-shore wind farms in a virtual power plant," Energy Policy, vol. 46, pp. 558-573, 2012. 
[8] M. Houwing, G. Papaefthymiou, P. W. Heijnen, and M. D. Ilić, "Balancing wind power with virtual power plants of microCHPs," in Proceedings of the IEEE Bucharest PowerTech, pp. 1-7, IEEE, Bucharest, Romania, July 2009.

[9] J. Mohammadi, A. Rahimi-Kian, and M. S. Ghazizadeh, "Joint operation of wind power and flexible load as virtual power plant," in Proceedings of the 10th International Conference on Environment and Electrical Engineering (EEEIC '11), pp. 1-4, Rome, Italy, May 2011.

[10] M. Peikherfeh, H. Seifi, and M. K. Sheikh-El-Eslami, "Optimal dispatch of distributed energy resources included in a virtual power plant for participating in a day-ahead market," in Proceedings of the 3rd International Conference on Clean Electrical Power: Renewable Energy Resources Impact (ICCEP '11), pp. 204210, Ischia, Italy, June 2011.

[11] D. Yi, Virtual Power Plant Stochastic Optimal Dispatch Considering Uncertain Outputs from Wind Generators, Changsha University of Science \& Technology, 2013.

[12] J. Xu, Study on Distributed Generation Dispatching Management Mode Base on Virtual Power Plant, North China Electric Power University, 2013.

[13] H. Pandžić, J. M. Morales, A. J. Conejo, and I. Kuzle, "Offering model for a virtual power plant based on stochastic programming," Applied Energy, vol. 105, pp. 282-292, 2013.

[14] E. Handschin, F. Neise, H. Neumann, and R. Schultz, "Optimal operation of dispersed generation under uncertainty using mathematical programming," International Journal of Electrical Power \& Energy Systems, vol. 28, no. 9, pp. 618-626, 2006.

[15] I. G. Moghaddam, M. Nick, F. Fallahi, M. Sanei, and S. Mortazavi, "Risk-averse profit-based optimal operation strategy of a combined wind farm-cascade hydro system in an electricity market," Renewable Energy, vol. 55, pp. 252-259, 2013. 


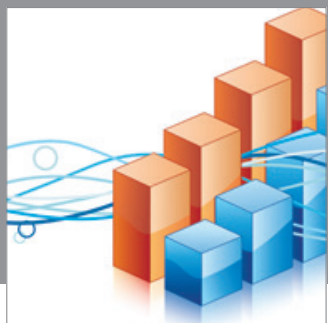

Advances in

Operations Research

mansans

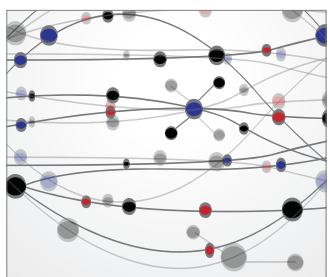

The Scientific World Journal
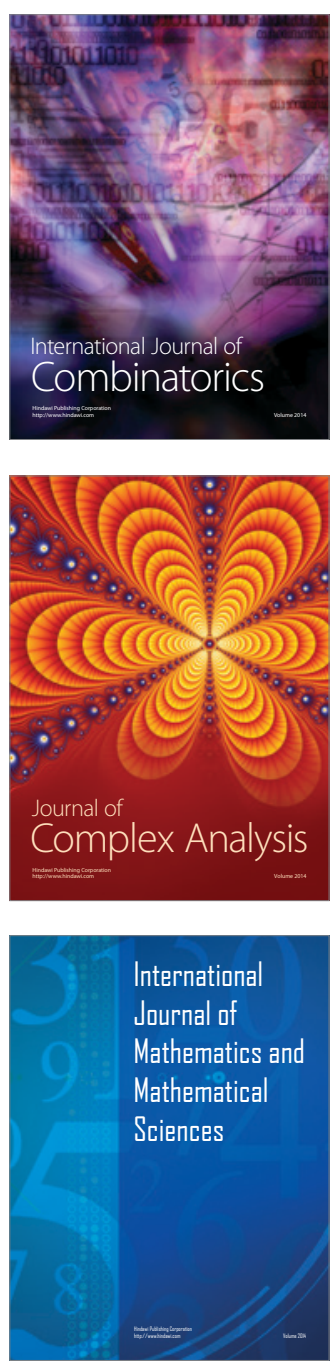
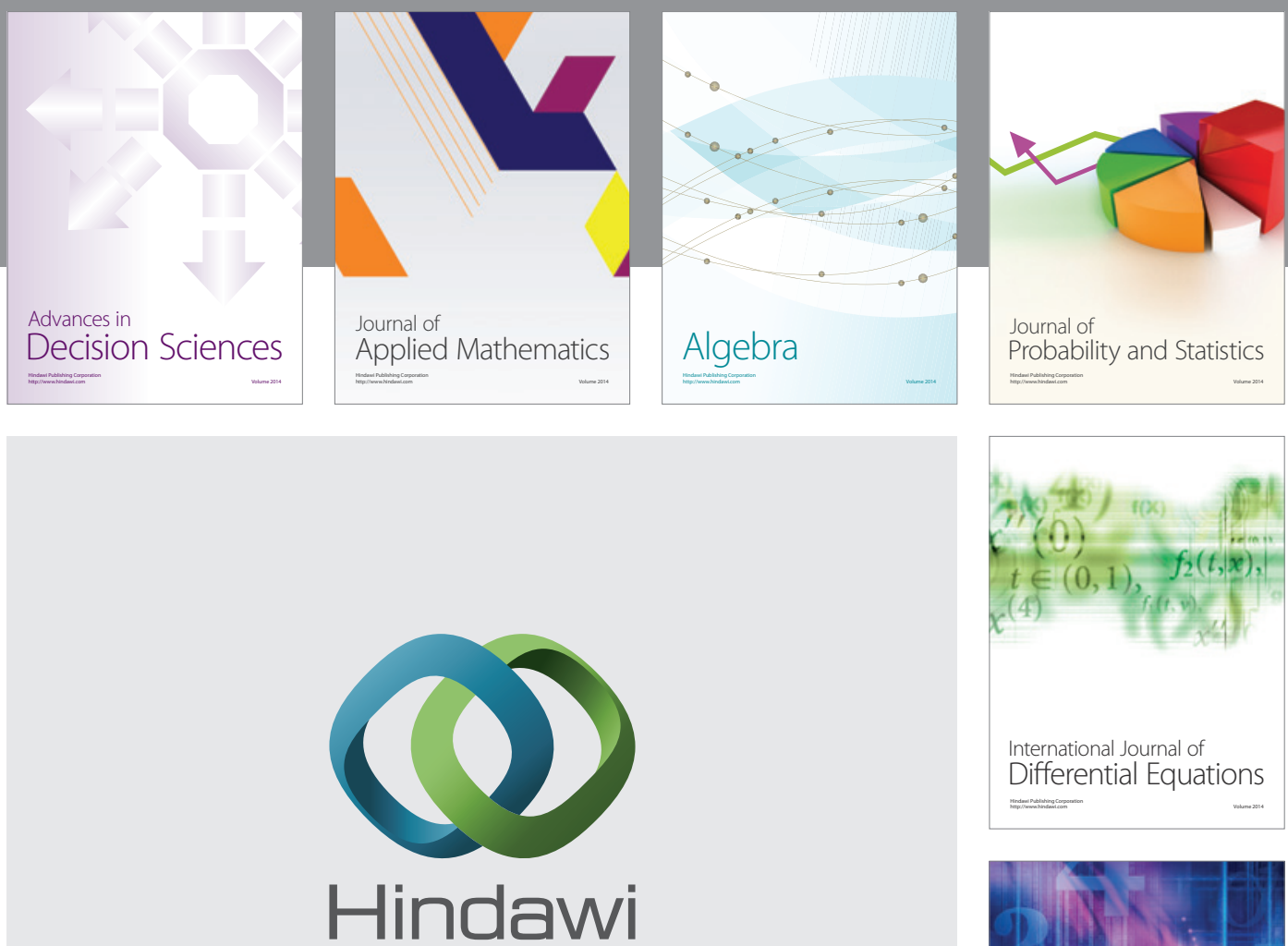

Submit your manuscripts at http://www.hindawi.com
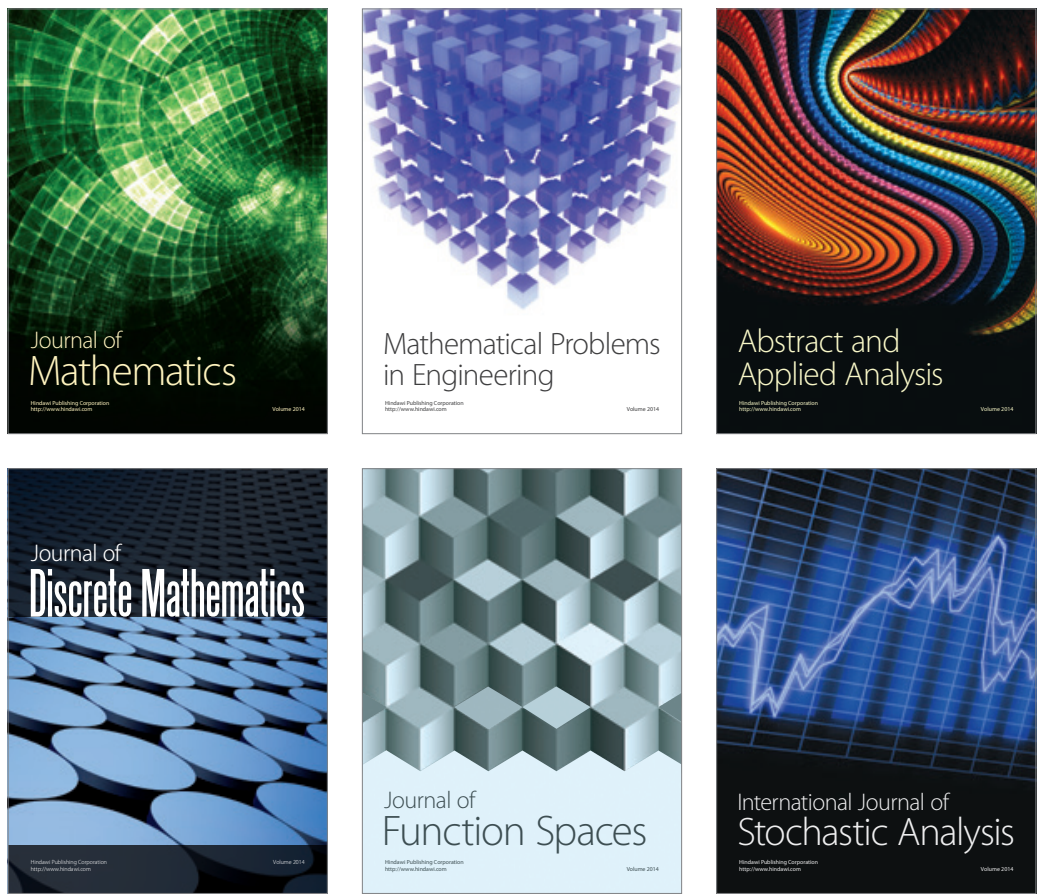

Journal of

Function Spaces

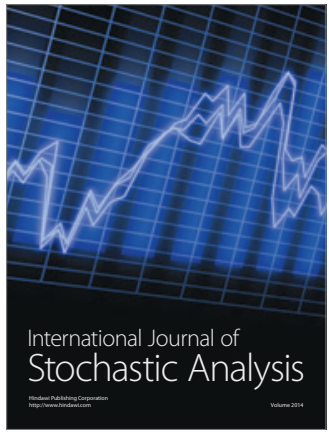

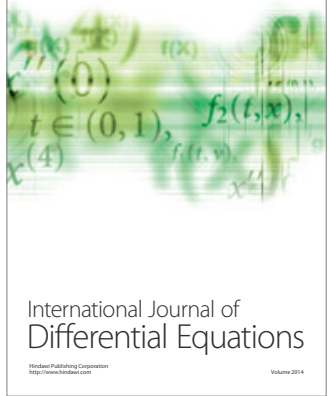
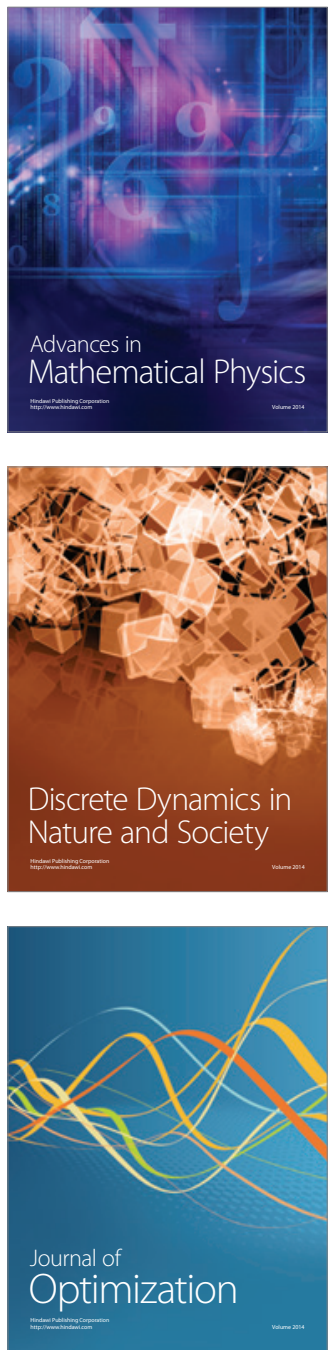